\title{
Insights from 180 years of mitochondrial variability in the endangered Mediterranean monk seal (Monachus monachus)
}

Philippe Gaubert ${ }^{10}{ }^{1,2}$ and Fabienne Justy, Institut des Sciences de l'Evolution de Montpellier (ISEM) - UM-CNRS-IRD-EPHE, Université de Montpellier, Place Eugène Bataillon - CC 64, 34095 Montpellier cedex 05, France; Giulia Mo, Istituto Superiore per la Protezione e la Ricerca Ambientale (ISPRA), via Vitaliano Brancati 48, 00144 Roma, Italy; Alex Aguilar, IRBio and Department of Evolutive Biology, Ecology and Environmental Sciences, Faculty of Biology, University of Barcelona, Diagonal 643, 08028 Barcelona, Spain; Erdem DANYer (D), Turkish Marine Research Foundation (TUDAV), PO Box 10 Beykoz, Istanbul, Turkey and Veterinary Control Central Research Institute, Ankara, Turkey; Asunción Borrell (D), IRBio and Department of Evolutive Biology, Ecology and Environmental Sciences, Faculty of Biology, University of Barcelona, Diagonal 643, 08028 Barcelona, Spain; Panagiotis Dendrinos, MOm/Hellenic Society for the Study and Protection of the Monk seal, Solomou Str. 18, 10682 Athens, Greece; BAYram Öztürk (D), Turkish Marine Research Foundation (TUDAV), PO Box 10 Beykoz, Istanbul, Turkey and Istanbul University, Faculty of Aquatic Sciences, Ordu Cad. No: 8 Laleli, Istanbul, Turkey; Roberta Improta, Museo Zoologico, Centro Musei delle Scienze Naturali e Fisiche, Università degli Studi di Napoli Federico II, Via Mezzocannone, 8 - 80134, Napoli, Italy; Arda M. Tonay (D), Turkish Marine Research Foundation (TUDAV), PO Box 10 Beykoz, Istanbul, Turkey and Istanbul University, Faculty of Aquatic Sciences, Ordu Cad. No: 8 Laleli, Istanbul, Turkey; Alexandros A. Karamanlidis (D), MOm/Hellenic Society for the Study and Protection of the Monk seal, Solomou Str. 18, 10682 Athens, Greece.

\section{Abstract}

Mediterranean monk seals (MMS) are among the most endangered marine mammals on Earth. We screened mitochondrial variability (control region [CR1] and mitogenomes) of the species through a 180-yr timeframe and extended by $20 \%(n=205)$ the number of samples from a previous investigation, including historical specimens from 1833 to 1975. Although we detected two new, rare CR1 haplotypes, genetic diversity remained extremely low. Fully resolved haplotype median network and rarefaction

\footnotetext{
${ }^{1}$ Corresponding author (e-mail: philippe.gaubert@univ-tlse3.fr).

${ }^{2}$ Current address: Laboratoire Evolution et Diversité Biologique (EDB) - UPS-CNRS-IRD, Université Paul Sabatier, 118 route de Narbonne, 31062 Toulouse, France.
} 
analysis both suggested low probability for further unscreened haplotypes. There was no clear phylogeographic structure across the 12 marine subdivisions covered by the species' range. Haplotypes previously considered diagnostic of the extant North Atlantic and eastern Mediterranean populations had their distributions extended into the western Mediterranean and the North Atlantic, respectively, by both historical and recent samples. Our study suggests that MMS have been genetically depauperate since at least the mid-19th century, and that the massive 1997 die-off in Western Sahara (North Atlantic) could have caused local haplotype extinctions. Our results support the hypothesis of past metapopulation dynamics across the species range, where the current segregation into geographically distant and genetically depauperate breeding populations (i.e., North Atlantic and eastern Mediterranean Sea) derives from the combined effects of historical extinctions, genetic drift on small breeding groups, and persistently low levels of genetic diversity.

Key words: ancient DNA, conservation genetics, genetic variability, Mediterranean monk seal, Mediterranean Sea, metapopulation, mitochondrial DNA, Monachus monachus, North Atlantic Ocean.

The Mediterranean monk seal, Monachus monachus, is considered the most endangered seal on Earth (Karamanlidis and Dendrinos 2015). The species once ranged from the Black and the Mediterranean Sea into North Atlantic waters from Cabo Blanco (Western Sahara) to northern Spain, including the Azores, Madeira, and the Canary Islands (González 2015, Karamanlidis et al. 2016a).

Mediterranean monk seals (MMS) have been subject to systematic exploitation by humans since prehistoric times (Johnson 2004, Stringer et al. 2008, Trantalidou 2011). Commercial exploitation was particularly intense during the Middle Ages in Madeira, the Canary Islands, and the Bay of Dakhla in Western Sahara (Brito 2012, González 2015). During the last two centuries, negative interactions with fishermen and growing human encroachment in coastal areas have resulted in the disappearance of the species from most of its former range (Kovacs et al. 2012, Karamanlidis et al. 2016a), with a current ratio of area of occupancy/extent of occurrence limited to $6.3 \%$ (Karamanlidis and Dendrinos 2015).

Extant populations are estimated to number fewer than 700 individuals, mostly distributed in the eastern Mediterranean Sea (Greece, Cyprus, and Turkey), at the Cabo Blanco peninsula (Western Sahara) and in Madeira, both in the North Atlantic (Karamanlidis et al. 2016a). MMS populations at Cabo Blanco and Gyaros Island in Greece are the only large aggregations that still preserve the structure of a colony (Martínez-Jauregui et al. 2012, Karamanlidis et $a l^{3}{ }^{3}$ ); all other populations in the eastern Mediterranean and Madeira consist of smaller, fragmented groups of 20-30 individuals maximum (Dede et al. 2015, Karamanlidis et al. 2016a, Ok and Gücü 2016). A reduced number of MMS may also persist along the coasts of

\footnotetext{
${ }^{3}$ Karamanlidis, A. A., S. Adamantopoulou, V. Paravas, M. Psaradellis and P. Dendrinos. 2013. Demographic structure and social behavior of the unique Mediterranean monk seal colony of the island of Gyaros (poster). Proceedings of the 20th Biennial Conference on the Biology of Marine Mammals (Volume 110). Otago University, Dunedin, New Zealand.
} 
eastern Morocco, Algeria, and Italy (Mo 2011, Mo et al. 2011), but their exact status is unknown.

Studies on the genetics of MMS have concentrated on the extant, remaining populations. Seminal investigations by Pastor et al. (Pastor et al. 2004, 2007) exploring nuclear genetic diversity identified (1) a severe bottleneck in the Cabo Blanco population and the absence of structure among local pupping colonies, (2) low genetic variability and substantial differentiation between the two main breeding populations in Cabo Blanco and Greece, which are separated by more than 4,000 km, and (3) a signature of metapopulation dynamics across the species' range in the recent past, probably disrupted from the Roman period, a time during which the regular exploitation of monk seals in the western and central Mediterranean was widespread (see Johnson and Lavigne 1999). A more recent study investigating the variability in the mitochondrial control region showed that MMS were among the most genetically depauperate mammals ever reported, with the existence of only five, closely related control region haplotypes (Karamanlidis et al. 2016b). Coupled with the sensitivity of isolated colonies of MMS to stochastic events including toxic algal blooms and/or viral outbreaks (Hernández et al. 1998, Borrell et al. 2007), such low levels of genetic diversity have been considered potentially deleterious to the recovery of the species (Pastor et al. 2004, 2007).

Because of the fragmented distribution of extant populations and their very low genetic diversity, scenarios for the demographic history of MMS and the time at which populations collapsed have remained speculative. In order to understand the ongoing process of a species' extinction, it is critical to take into account its past genetic diversity (e.g., Foote et al. 2013, Casas-Marce et al. 2017). To reach such an objective, access to historical specimens-notably from museum collections-is a critical step because such material often represents, especially in the case of endangered and/or elusive species, extinct or rare populations (Suarez and Tsutsui 2004, Spurgin et al. 2014). In the case of the MMS, museum samples are the only source yet to be assessed for studying the impact of the historical, local extinctions that drastically fragmented the species' range (Sergeant et al. 1978).

Building on the recent study of Karamanlidis et al. (2016b), we reassess the genetic variability patterns in extant MMS by sequencing 40 new samples, including 25 historical specimens, from the historical and current species' range. More specifically, we analyze control region sequences and mitogenomes to address the following questions: (1) was the Mediterranean monk seal already a genetically depauperate species in the recent past? and 2) is there a signature of past metapopulation dynamics that would have connected the two main breeding colonies in the North Atlantic Ocean and the eastern Mediterranean Sea? We also discuss the applicability of mitochondrial markers in the conservation genetics of MMS.

\section{Methods}

\section{Sampling}

We obtained 16 recent (1989-2014) samples of MMS from various tissue banks and collections, originating from Greece (3), Turkey (2), Croatia (1), 


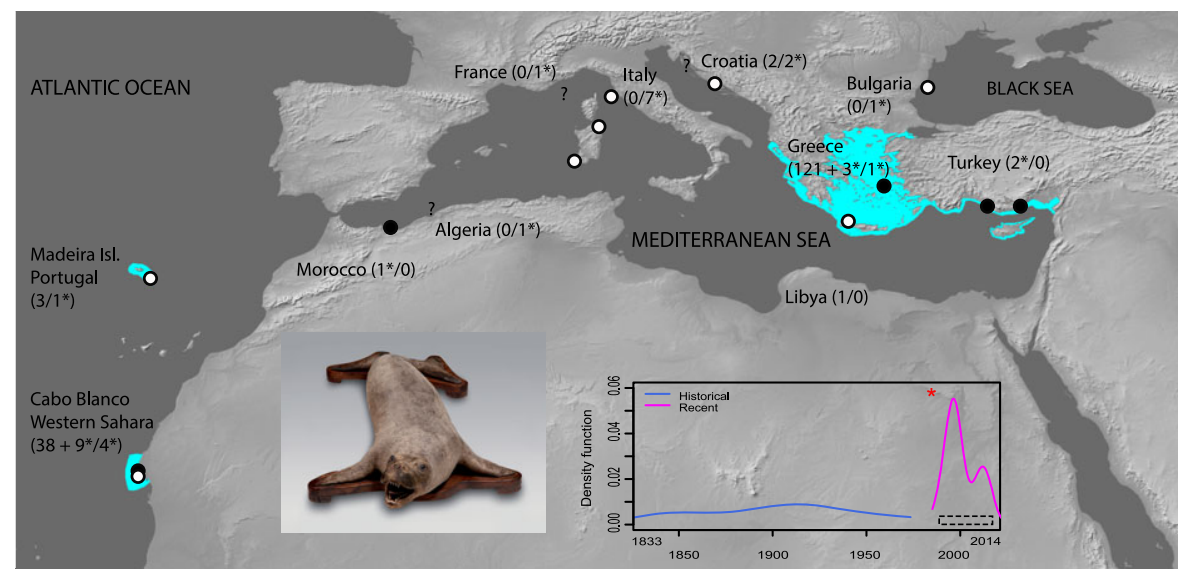

Figure 1. Distribution of samples of Mediterranean monk seals with known origin used in this study. In light blue, extant distribution of the species. Black and white circles correspond to recent and historical specimens, respectively, newly sampled as part of this study. Question mark means uncertain location. Between brackets, the respective contribution of recent/historical samples per locality; asterisks indicate new samples (relative to Karamanlidis et al. 2016b). At the bottom right, kernel density plots of the historical versus recent sample distribution through time as used in this study. The dotted box represents the timeframe (1990-2012) covered in Karamanlidis et al. (2016b). The red asterisk marks the mass die-off at Cabo Blanco, North Atlantic Ocean, in 1997. The photograph represents the sole Mediterranean monk seal ever collected from the Gulf of Naples, Italy in 1884 (Centro Musei delle Scienze Naturali e Fisiche of the University of Naples "Federico II" specimen Z245; not used in this study).

Western Sahara ("Cabo Blanco"; 9), and Morocco (1) (see Table S1). We also sampled 24 "historical" (1833-1975) specimens of MMS from 14 natural history museums that represent both the extant and historical species' range (Fig. 1). The distinction between recent (from 1989 on) and historical (prior to 1975) samples reflects the fact that the last records of resident MMS groups from the central and western Mediterranean Sea were reported during the 1970s (Johnson 2004), suggesting that after this period the fragmentation of the species' range into North Atlantic and eastern Mediterranean populations as we know it today was effective. The historical samples originated from Bulgaria (Black Sea; 1), Croatia (2), France (1), Greece (Crete Island; 1), Italy (9; including Sardinia, Elbe Island, Capraia Island), Algeria (1), Portugal (Madeira; 1) and Western Sahara (4), plus four samples that had no precise origin. Among the historical samples, three had no exact dates of collection (but those were antecedent to 1975 according to the curators). The relative distribution of historical $v s$. recent samples was visualized using Kernel density plots reconstructed in RStudio v. 1.1.383 (RStudio Team 2015) with the function density (Fig. 1).

\section{DNA Extraction}

Genomic DNA was extracted from fresh tissue and skin samples using the DNeasy Blood \& Tissue Kit (QIAGEN, Courtaboeuf, France) following 
the manufacturer's recommendations. To avoid cross-sample contamination, the historical samples including bones (postcranial and turbinal bones), tanned skins and connective tissues were processed in series of small batches (ca. 10 samples each) with negative controls through each extraction step in a laboratory dedicated to degraded DNA (http://www.labex-cemeb.org/en/degraded-dna), isolated from the other lab facilities where fresh tissues were processed. A subset of 10 historical samples was extracted 2-3 times independently and sequenced to control for potential cross-contamination and mismatch repair. The replicate sequences were identical for each of the 10 individuals (data not shown). Small pieces of tanned skin and connective tissue were extracted using the DNeasy Blood \& Tissue Kit protocol, adding $4 \mu \mathrm{L}$ of DTT (1M) during the lysis step and an additional $20 \mu \mathrm{L}$ of proteinase K. Final elution volumes for fresh and tanned skin/connective tissue samples were 120 and $60 \mu \mathrm{L}$ $\mathrm{H}_{2} \mathrm{O}$, respectively.

The protocols for reducing bones into powder varied depending on sample type. Turbinal bones were reduced to powder with the Bullet Blender Homogenizer using 2-3 stainless steel balls (Next Advance, Troy, NY) in Safe-Lock $2 \mathrm{ml}$ tubes (Eppendorf, Montesson, France) for three minutes at speed 10. Postcranial bones were first cleaned with a tissue soaked in bidistillate water, and their outer surface was removed using scalpel blades. Postcranial bones were then wrapped in aluminum foil and ground into coarse powder using a hammer cleaned with $6 \%$ diluted bleach between each sample.

Approximately 50-100 mg of bone powder was digested in 1-1.5 mL lysis buffer composed of 0.5M EDTA pH 8.0, 0.5\% N-lauryl sarcosyl and $0.25 \mathrm{mg} / \mathrm{mL}$ proteinase $\mathrm{K}$ overnight at $56^{\circ} \mathrm{C}$ with gentle mixing. Purification and elution were performed with the MinElute PCR Purification Kit (QIAGEN) following the manufacturer's instructions. Final elution volume was $60 \mu \mathrm{L} \mathrm{H}_{2} \mathrm{O}$.

\section{PCR Amplification of Control Region and Mitogenome Shotgun Sequencing}

We amplified $524 \mathrm{bp}$ of the hypervariable region I of the mitochondrial control region (CR1) from the fresh samples using the primer pair of Karamanlidis et al. (2016b). For the historical samples, we designed four specific primer pairs with the Primer3 web platform (http:// primer3.ut.ee/) amplifying partially overlapping fragments $\leq 150 \mathrm{bp}$ (Table 1), to obtain a $484 \mathrm{bp}$ fragment encompassing all the variable sites of CR1 observed in MMS (Fig. 2). In this case, negative DNAextraction controls (see above) were included along with PCR blank controls to further assess potential contamination. PCR amplifications were carried out for both the large and small fragments in $20 \mu \mathrm{L}$ final volume containing 5-50 ng of template DNA (as determined using Nanodrop), $0.1 \mathrm{mg} / \mathrm{mL}$ BSA, $4 \times 0.25 \mathrm{mM}$ dNTPs, $2 \times 0.2 \mathrm{mM}$ primers, $1 \times$ PCR direct loading buffer with $\mathrm{MgCl}_{2}(1.5 \mathrm{mM})$ and $0.5 \mathrm{U}$ GoTaq Flexi DNA Polymerase (Promega, Charbonnières-les-Bains, France). PCR cycling conditions included a first step of denaturation $\left(94^{\circ} \mathrm{C}, 2 \mathrm{~min}\right)$, followed by $40-45$ cycles of denaturation $\left(92^{\circ} \mathrm{C}, 30 \mathrm{~s}\right)$, annealing (30 s; see Table 1 


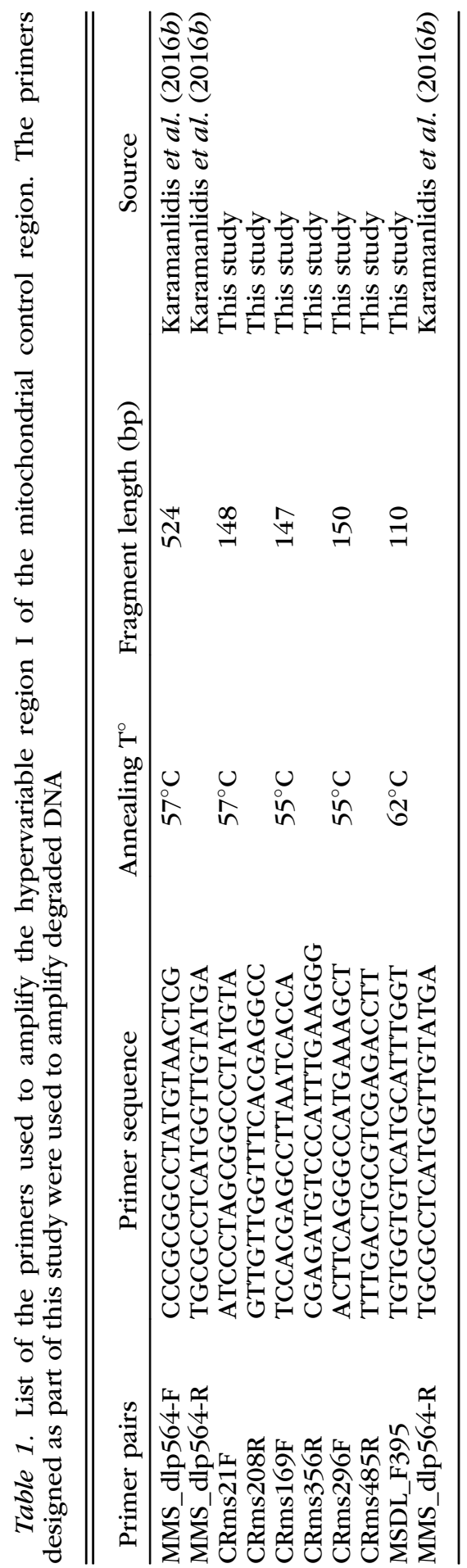




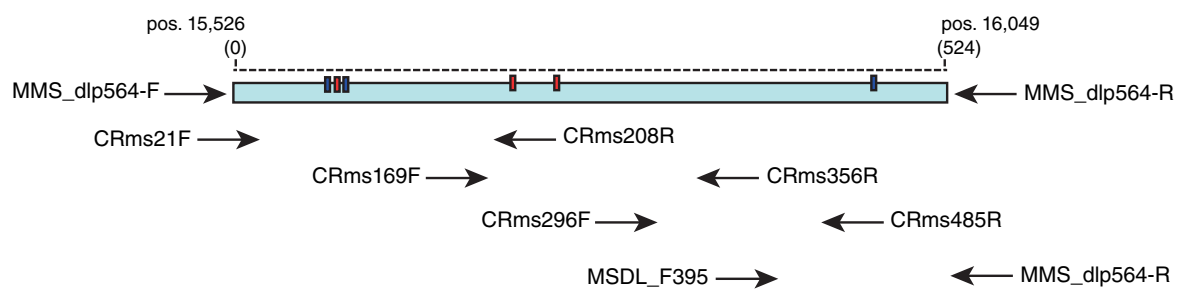

Figure 2. Primer design used in this study to amplify the hypervariable region I of the mitochondrial control region. Site positions (pos) refer to the mitogenome of Mediterranean monk seal with GenBank Accession number MG570472. Red and blue boxes on the control region sequence indicate new (this study) and previously known polymorphic sites, respectively. Primer details are given in Table 1.

for primer-specific temperatures) and extension $\left(72^{\circ} \mathrm{C}, 30 \mathrm{~s}\right)$, and a final extension step $\left(72^{\circ} \mathrm{C}, 15 \mathrm{~min}\right)$. PCR products were purified and sequenced in both directions on a AB3130xl Genetic Analyzer (Applied Biosystems, Foster City, CA) at the technical facilities of the genotyping and sequencing platform of the Institut des Sciences de l'Evolution de Montpellier (ISEM). We completed our data set with the 165 sequences produced by Karamanlidis et al. (2016b) (GenBank accession numbers: KT935307-935311), covering the extant species' range (Greece [121], Croatia [2], Libya [1], Western Sahara [38] and Madeira [3]). Nucleotide sequences were visually aligned with BioEdit 7.1.3 (Hall 1999). The final CR1 alignment included 204 sequences (MS24 was not sequenced for CR1 because already available in GenBank; see Table S1).

Five mitogenomes of MMS were obtained by shotgun sequencing, from four recent specimens in the eastern Mediterranean (Greece, Turkey, and Croatia) and one in the North Atlantic Ocean (Western Sahara) (see Table S2). Libraries were prepared after Tilak et al. (2015) and equimolarly pooled on different lanes, each combining $c a$. 20 vertebrate taxa. Lanes were sequenced using single- or paired-end $100 \mathrm{bp}$ reads on an Illumina HiSeq2000 Analyzer at GATC Biotech, Konstanz, Germany. Quality of raw genomic data were checked with FastQC (https://www.bioinformatics. babraham.ac.uk/projects/fastqc/) and Geneious v.7.1.5 (Biomatters, Auckland, New Zealand) was used to trim Illumina adapters from raw reads before assembly. Given the absence of a complete mitogenome of MMS in the databanks, we used the annotated mitogenome of the Hawaiian monk seal Neomonacus schauinslandi (NC_008421) as a reference for mapping our sample with best coverage (MS24; see Table S2) in Geneious. Reads were first mapped using the "medium-low sensitivity" option, followed by "low sensitivity" iterative mapping repeated until no additional reads could be included. The final consensus sequence was obtained using the highest quality base assignment threshold; nucleotides were called for sites covered by $\geq 3$ reads. The four other mitogenomes of MMS were assembled from the MS24 consensus sequence. A CR1 fragment was also generated by PCR (see above) from the five samples to validate the "quality" (i.e., $100 \%$ match) of the assembled mitogenomes. Final alignments of the 204 CR1 sequences and the five mitogenomes were performed in 
Geneious using the Muscle algorithm (Edgar 2004) with default parameters and were manually adjusted in BioEdit.

CR1 and mitogenome sequences were deposited in GenBank (accession numbers MG570469-570475; Tables S1, S2).

\section{Genetic Diversity and Variability}

Genetic diversity within MMS was calculated for the CR1 in DnaSP v. 6.10.01 (Rozas et al. 2017), including number of haplotypes (b) and polymorphic sites $(S)$, haplotype diversity $(H d)$ and nucleotide diversity $(\pi)$. Genetic diversity estimates were also calculated for the historical (1833-1975; $n=24)$ and recent (1989-2014; $n=180)$ samples, separately.

In order to assess haplotype geographic distribution, we built a medianjoining network (Bandelt et al. 1999) in Network v. 5.0.0.1 (http://www. fluxus-engineering.com) with $\varepsilon$ fixed to 50 (maximal pairwise difference $=$ 5 ; character weights $=10 ; \mathrm{tv} / \mathrm{ts}$ weight $=1: 1$ ) to obtain a full median network (Polzin and Daneshmand 2008).

Because of the extremely low level of CR1 variability within MMS (see Karamanlidis et al. $2016 b$ and this study), we refrained from using the calculation of $F_{\mathrm{ST}}$ for estimation of population differentiation. Indeed, such relative measures of divergence can be drastically affected by levels of within-population genetic diversity (Meirmans and Hedrick 2011, Jakobsson et al. 2013), making them potentially unfit to measure differentiation within a species where genetic diversity is low. Because of these limitations, we restricted ourselves to the description of the genetic variability among and within populations of the MMS. For this purpose, we counted the number of nucleotide differences among sequences using MEGA v. 7.0.18 (Kumar et al. 2016), delineating 12 marine subdivisions (Table 2$)$ of the Mediterranean Sea $(n=9)$, Black Sea $(n=1)$ and the North Atlantic Ocean $(n=2)$ as defined by the International Hydrographic Organization (1953).

In order to assess the relationship between the number of haplotypes and sample size, we used EstimateS v. 9.1.0 (Colwell 2013) and the multinomial model (Colwell et al. 2012) to compute an individual-based rarefaction curve from CR1 sequences. We extrapolated the rarefaction curve by a factor of 2 (total $n=408$ ) to evaluate the trend in haplotype diversity in the case of extended sampling. We also ran 100 randomizations to calculate the bias-corrected Chao 1 estimator, which estimates the "true" diversity of a sample set (Chao 1984, Chao et al. 2015).

We used the five complete mitogenomes generated in this study to assess gene-specific polymorphism for the 13 coding genes (CDS), the two ribosomal genes (rRNA) and the control region. To do so, we calculated the total number of differences between individuals from the two main breeding populations of MMS (eastern Mediterranean Sea and North Atlantic Ocean).

\section{RESULTS}

Density curves showed that the temporal distribution of samples across the historical period was relatively uniform from 1833 to 1975 


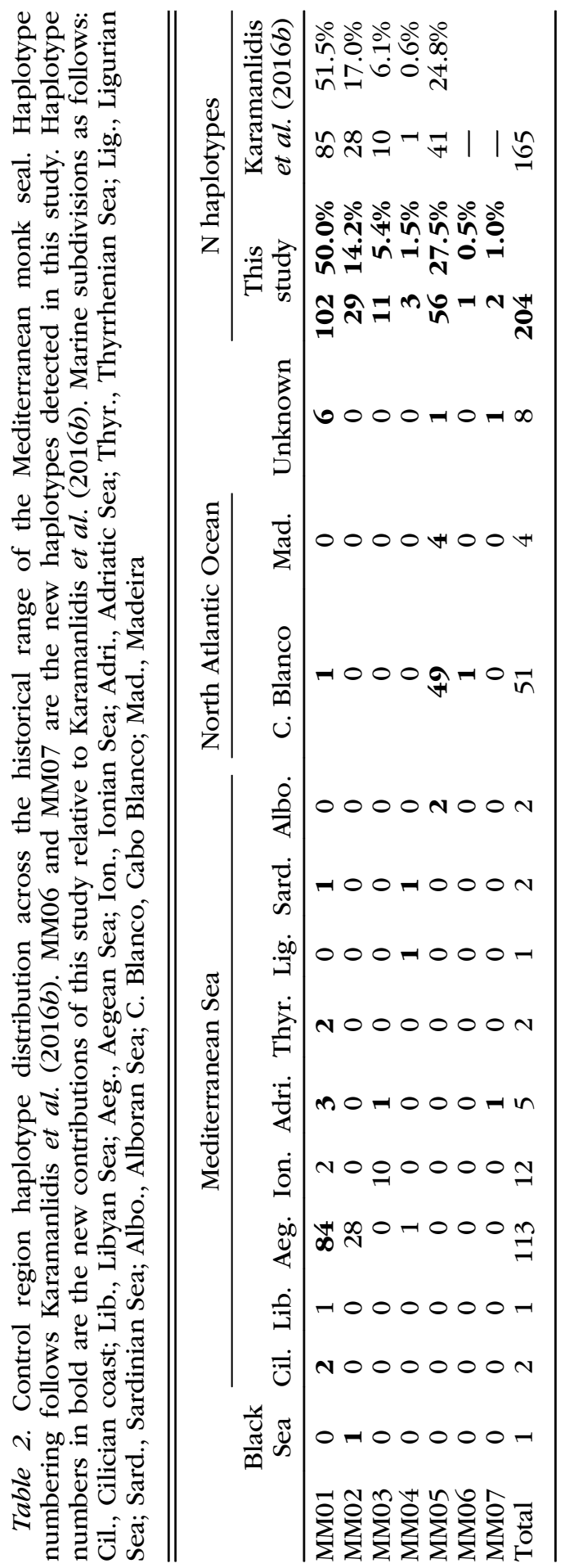




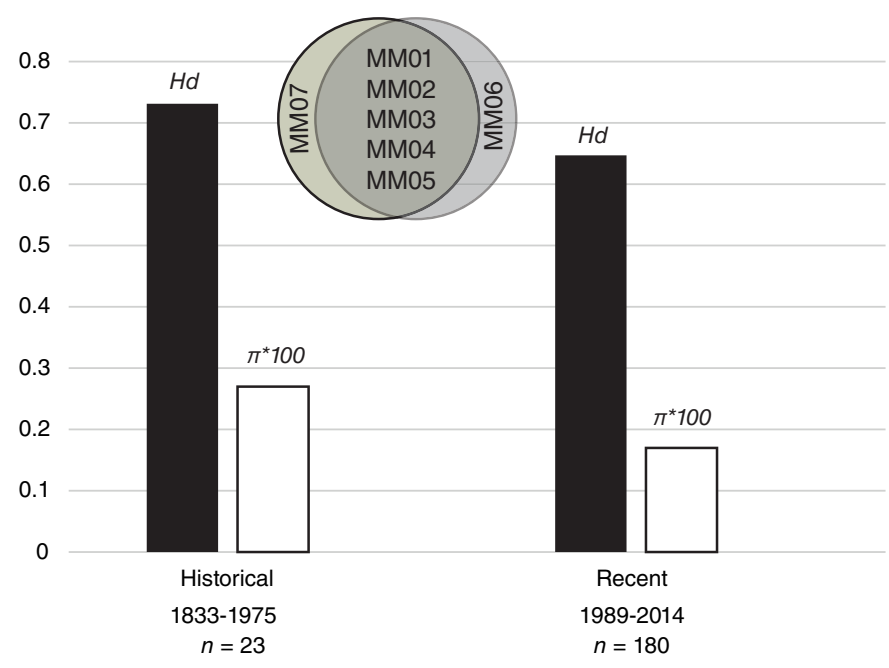

Figure 3. Genetic diversity estimates between historical and recent samples. $H d$ : Haplotype diversity; $\pi$ : Nucleotide diversity. At the top, Venn diagram illustrating the distribution of haplotypes between the historical (left circle) and recent (right circle) samples.

compared to the recent period (1989 to 2014) where the distribution was clearly bimodal, notably because of an excess of samples coming from the massive die-off at Cabo Blanco in 1997 (Fig. 1). Mitogenomes produced from the five recent samples had a total length ranging from 16,739 to 16,747 , their mean depth varying between $13 \times$ and $625 \times$, and low levels of base ambiguities (4-11) (Table S2). The CR1 fragments aligned with positions 15,526 (or 15,566 in the case of shorter fragments; see above) and 16,049 of the mitogenomes (Fig. 2).

CR1 diversity indices for the total sample set $(n=204$ sequences; length $=484 \mathrm{bp}$ ) were as follows: $h=7 ; S=6 ; H d=0.654 ; \pi=0.0018$. Genetic diversity was slightly higher for historical samples $(n=24)$ compared to recent samples $(n=180): S_{\mathrm{his} / \mathrm{rec}}=5 / 4 ; H d_{\mathrm{his} / \mathrm{rec}}=0.731 / 0.647 ; \pi_{\mathrm{his} / \mathrm{rec}}$ $=0.0027 / 0.0017$ (Fig. 3). Both sample sets were composed of six haplotypes, of which five were shared, meaning that both historical and recent samples also hold a unique, single haplotype each.

Two new haplotypes were identified, including MM06 (Cabo Blanco; one recent sample, but see Discussion) and MM07 (Adriatic Sea and France; two historical samples) (Tables 2, S3). The CR1 full median network did not include median vectors (i.e., missing haplotypes; Fig. 4). There was no apparent geographic structuring among the seven haplotypes, and all differed by 1-2 mutations (transitions). The most common haplotype (MM01; 50\% of the samples) was distributed from the eastern Mediterranean Sea (Turkey; two samples) to Cabo Blanco (North Atlantic Ocean, Western Sahara; 1), also including Libya (1), Aegean Sea (Greece; 


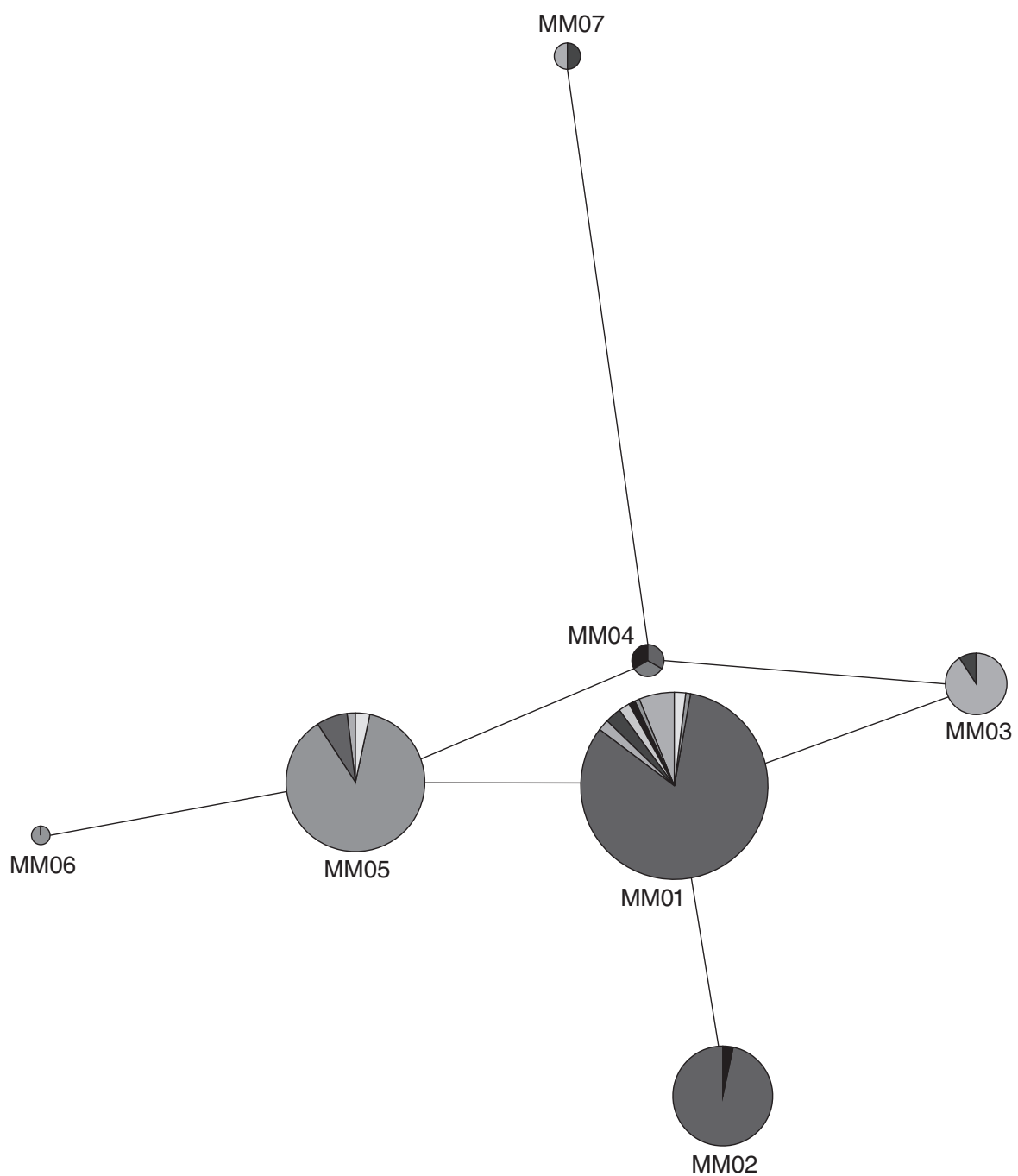

Figure 4. Full median network based on the hypervariable region I of the mitochondrial control region in Mediterranean monk seals. All the haplotypes are separated by one mutation, except MM04 and MM07 (two mutations). Haplotype numbers refer to Tables 2, S1. Haplotype distribution as follows: MM01: Cilician Coast (2), Libyan Sea (1), Aegean Sea (84), Ionian Sea (2), Adriatic Sea (3), Thyrrenian Sea (2), Sardinian Sea (1), Cabo Blanco (1), unknown marine subdivision (6); MM02: Black Sea (1), Aegean Sea (28); MM03: Ionian Sea (10), Adriatic Sea (1); MM04: Aegean Sea (1), Ligurian Sea (1), Sardinian Sea (1); MM05: Alboran Sea (2), Cabo Blanco (49), Madeira (4), unknown (1); MM06: Cabo Blanco (1); MM07: Adriatic Sea (1), unknown (1).

84), Ionian Sea (Greece; 2), Adriatic Sea (Croatia; 3), Thyrrenian Sea (Italy; 2), Sardinian Sea (Italy; 1), and six unknown localities. The second most common haplotype (MM05; ca. 28\%) was distributed across the North 
Atlantic Ocean (Cabo Blanco and Madeira; 53) and in the Alboran Sea (Morocco and Algeria; 2). MM02 (ca. 14\%) was present in the Black Sea (Bulgaria; 1) and the Aegean Sea (28). MM03 (ca. 5\%) occurred in the Ionian Sea and Adriatic Sea. MM04 (1.5\%) was present in the Aegean Sea, Ligurian Sea, and Sardinian Sea.

Mean numbers of differences among marine subdivisions were extremely low, ranging from 0 to 3 with minimum and maximum values between 0 and 5 (Table S4). Mean variability within marine subdivisions ranged between 0 and 2.67, with the highest values in the Adriatic Sea (2.67) and the Sardinian Sea (2). The individual-based rarefaction curve and its $95 \%$ intervals almost reached horizontal asymptotes after extrapolation by a factor of 2 , with $\mathrm{N}$ haplotypes slightly above 7 (Fig. S1). Chao 1 estimator value was 7 (7-8.1395\% CI).

The total number of differences across mitogenomes between the eastern Mediterranean and Cabo Blanco individuals was $0.3 \%$ (Table S5). Only seven genes out of 16 showed polymorphism. Among those, six genes (12s, cox1, cox2, nad4, nad5, cytb) showed very low levels of variability $(0.1 \%-0.4 \%)$. The control region had a higher level of polymorphism, totaling 31 differences (2.4\%).

\section{Discussion}

\section{Mediterranean Monk Seals Have Been Genetically Depauperate for at Least $180 \mathrm{Yr}$}

The use of historical samples allows for a direct assessment of genetic diversity loss over time (Rosenbaum et al. 2000). In the case of genetically depauperate species under extinction risk, the analysis of historical samples may allow investigation of whether human activities have had a direct impact on the loss of genetic diversity (Matocq and Villablanca 2001, Wandeler et al. 2007, Casas-Marce et al. 2017).

Screening the mitochondrial diversity of MMS over the last $c a .180 \mathrm{yr}$ has shown that the species had already been genetically depauperate since at least the mid-19th century. Despite the detection of two new, rare haplotypes ( $h=7$; see below), CR1 diversity indices were among the lowest within pinnipeds and other endangered species, even though the percentage of variable sites almost doubled (from $0.6 \%$ to $1.1 \%$ ) compared to Karamanlidis et al. (2016b). The ratio between haplotype numbers and the total number of samples $(7 / 204=0.03)$ was the same as that reported in Karamanlidis et al. (2016b) for 165 recent samples covering the current species' range. Such low levels of mitochondrial diversity correspond to levels observed in other mammalian species at the brink of extinction (Rosel and Rojas-Bracho 1999, Rosenbaum et al. 2000, Weber et al. 2000, Johnson et al. 2004, Rodriguez et al. 2011, Casas-Marce et al. 2017).

Despite the analysis of 40 new samples (including 25 historical samples), we detected only two new CR1 haplotypes at very low frequencies (MM06-MM07: 0.5\%-1.0\%). This, coupled with the fact that (1) rarefaction analysis - including extrapolation-and Chao 1 estimator neared the total number of haplotypes (7) found in this study (Fig. S1) and (2) the 
full median network of CR1 haplotypes did not call for hypothetical (i.e. missing) haplotypes, suggests that the probability of detecting additional haplotypes in MMS through the last $180 \mathrm{yr}$ is low, in turn reinforcing the current pattern of low genetic diversity in the species.

Our results also bear witness to the deleterious impact of local extinctions on the genetic variability of a patchily distributed species such as the Mediterranean monk seal. Indeed, haplotype MM07, which was recorded in two historical samples from France (collected before 1850) and Croatia ("Dalmatia"; probably collected before the First World War), is probably extinct because it could not be detected in the 180 recent samples that have been sequenced so far (Karamanlidis et al. 2016b; this study). Moreover, the sequencing of MMS specimens held at the Estacion Biologica de Doñana (Table S1) and originating from the Cabo Blanco 1997 die-off, enabled the identification of two haplotypes that were not described in this colony by Karamanlidis et al. (2016b). We speculate that the die-off, which reduced the size of the Cabo Blanco population by two-thirds (Hernández et al. 1998), could have led to the extinction of those two haplotypes, each represented by a single individual, including MM06 (new haplotype, endemic) and MM01 (shared with the Mediterranean). Therefore, it is of utmost importance to conduct genetic analyses on samples from Cabo Blanco collected after the massive dieoff in order to assess the impact of this dramatic demographic event on the genetic diversity of MMS.

The Mediterranean monk seal was already considered critically endangered when the first in situ research and conservation efforts were initiated in the late 1970s (Ronald and Duguy 1979). Although MMS have been exploited by humans since the Late Pleistocene (Steele and ÁlvarezFernández 2011), more recent exploitations are believed to have caused major local extinctions, notably by Romans in the Mediterranean Sea (until $300 \mathrm{AD}$ ) and by European sealing expeditions in the Atlantic Ocean (14-16th centuries) (Marchessaux 1989, Johnson and Lavigne 1999, González 2015). Following deliberate killing by fishermen and the development of mass tourism during the 20th century, breeding populations of MMS disappeared in the southern Black Sea, Albania, Croatia, Egypt, Israel, Italy, Lebanon, Libya, Tunisia, and Syria (Karamanlidis et al. 2016a). Earlier in the 20th century, MMS also went extinct in France (mainland coast and Corsica), Spain (mainland coast and Balearic Islands) and the northern Black Sea (Sergeant et al. 1978, Marchessaux 1989).

Although such extinctions have most probably deeply impacted the distribution and demography of the species, our results indicate that the global level of mtDNA diversity in MMS remained roughly constant from the mid-19th century on. Indeed, we observed only a slight decrease in genetic diversity between historical and recent samples, and the number of haplotypes (six) remained the same between the two periods (Fig. 3). It seems reasonable to assume that in the timeframe of our study period, which covers $c a .180 \mathrm{yr}$, human activities did not significantly affect the mitochondrial diversity of the species.

Thus, it is not known whether human pressure exerted on MMS through historical times is responsible for the extremely low level of genetic variability observed in our study. In the Hawaiian monk seal, 
which shares with MMS one of the lowest levels of genetic diversity among mammals, there is evidence for a bottleneck due to hunting activities in the late 19th century, but also for the existence of low levels of heterozygosity before exploitation (Schultz et al. 2009, 2010). Schultz et al. (2010) speculated that a combination of long-term small population size and a bottleneck due to ancient-to-recent hunting activities depleted the genetic diversity of the Hawaiian monk seal. This could also be the case in MMS, although the exact impact of antique hunting activities such as those exerted during classical antiquity by Romans in the Mediterranean (Johnson and Lavigne 1999) is difficult to assess. Conversely, the dramatic decline of North Atlantic populations is more thoroughly documented, and seems to be linked to the heavy exploitation by Portuguese sailors for fur and oil during the 15th-16th centuries (Monod 1932, Marchessaux 1989, Pastor et al. 2004). Furthermore, the negative impact of sealing operations on the survival of North Atlantic MMS could have been further accentuated by unfavorable geoclimatic events also contributing to local extinctions, with the disappearance of (1) breeding sites in the Macaronesia Islands (Azores, Madeira, Canarias, Cabo Verde) following Late Pleistocene sea-level rise and (2) the whole Lobos Island (Bay of Dakhla, Western Sahara) after a tsunami caused by the "Lisbon earthquake" in 1755 (González 2015).

Given the very low levels of genetic diversity observed in the two surviving species of monk seals (see above) and the extinction proneness observed within the Monachinae in general (the third modern species, Neomonachus tropicalis, became extinct in the 1950s; McClenachan and Cooper 2008), low genetic diversity may actually constitute an intrinsic characteristic of monk seals since their early history ca. 6.3 MYA (Scheel et al. 2014). There are several, superimposable factors that may maintain low genetic diversity through time, including long-term small effective population sizes, recurrent population crashes, low juvenile survival, low reproductive success (Matocq and Villablanca 2001, Milot et al. 2007), and genome-wide selective sweep (Amos and Harwood 1998). Low birth rates and high pup mortality have been proposed as the factors maintaining small populations in MMS from Cabo Blanco (before the dieoff) and also Hawaiian monk seals (Gazo et al. 2000, 2001; Schultz et al. 2009). The paucity of the data related to the population dynamics of MMS and the great influence of environmental and demographic conditions on those parameters (Karamanlidis et al. 2016a) renders low recruitment as a more reasonable hypothesis to explain slow population growth (Martínez-Jauregui et al. 2012), and by extension, long-term small effective population sizes. However, large-scale studies including both Atlantic and Mediterranean populations will have to be conducted to identify the main factors responsible for the low genetic diversity observed in MMS.

\section{A New Picture of Mitochondrial Variability Across the Historical Range of the Mediterranean Monk Seal}

Our study documented a less geographically confined mitochondrial haplotype distribution than previously assumed (Fig. 4, Table 2), suggesting that historical, local extinctions-but also the sampling bias towards extant 
populations of previous studies-yielded an "actualistic" interpretation of the clear-cut separation between the eastern Mediterranean Sea and the North Atlantic Ocean. All the five previously identified CR1 haplotypes (Karamanlidis et al. 2016b) were found to have wider, sometimes overlapping distributions. Notably, we showed that MM01, thought to be diagnostic of the eastern Mediterranean breeding population (Harwood et al. 1996, Karamanlidis et al. 2016b), was not restricted to the Aegean, Ionian, Adriatic, and Libyan Sea. Rather, it also characterized the first-ever sequenced samples from the Cilician Coast (East; Danyer et al. 2013, 2014), historical samples from the Western Mediterranean, in the Thyrrenian and Sardinian Seas, and a new sample from the massive die-off at Cabo Blanco, ca. 4,000 km West (Table 2). Similarly, we showed that MM05, previously thought to be the unique haplotype in the North Atlantic, was also detected in the western Mediterranean (Alboran Sea) from one recent (Morocco) and one historical (Algeria) sample. MM02, distributed in the central and northern Aegean Sea (Karamanlidis et al. 2016b), was also found in the first-eversequenced representative of the extinct population of the Black Sea (Kiraç 2011). Despite uneven sampling in the Black Sea, our results suggest that dispersal probably occurred across the Turkish Straits System (TSS, consisting of the Marmara Sea, Istanbul and Çanakkale Straits), where individuals were observed in 2014 (southern Sea of Marmara; Inanmaz et al. 2014, Dede et al. 2016).

MM04, a rare haplotype initially found in a single individual from the Aegean Sea (Karamanlidis et al. 2016b), was detected westward in two historical samples from the Ligurian and Sardinian seas. Given the low frequency of this haplotype in the Aegean Sea $(<1.0 \%)$ and the relatively low number of samples from the Italian seas $(n=9)$, detecting MM04 in more than $20 \%$ of the Italian samples could be an indication of a haplotype once frequent in the Italian seas and now at the brink of extinction. Further sampling will have to be conducted to assess whether the small surviving colonies that might inhabit the Tyrrhenian-Sardinian-North African waters (Mo 2011) represent one of the last sources for this haplotype, or if MM04 originates from the Eastern Mediterranean recovering population.

The two main areas currently inhabited by the MMS are separated by $c a$. $4,000 \mathrm{~km}$, and appear to be genetically isolated (Harwood et al. 1996; Pastor et al. 2004, 2007; Karamanlidis et al. 2016b). However, the sharing of haplotypes between the North Atlantic Ocean and the Mediterranean Sea populations supports the hypothesis that in the past, MMS constituted a metapopulation with gene flow connecting the Atlantic all the way to the Black Sea possibly via geographically intermediate populations that have now gone extinct (Pastor et al. 2007). The widespread distribution of two haplotypes found in our study, together with the greater levels of genetic variability observed in four marine subdivisions (Cabo Blanco, Aegean Sea, Adriatic Sea, and Sardinian Sea; Table S4), support the assumption of historical gene flow connecting the North Atlantic to the eastern Mediterranean, notably involving the passage through the Strait of Gibraltar in the west. Thus, one of the main conclusions from our analysis is that the current genetic separation between North Atlantic and eastern Mediterranean breeding populations might not have been effective in the past. The current pattern of low genetic diversity and population isolation observed in 
MMS is likely explained by a series of local, historical extinctions coupled with the effect of genetic drift on small breeding populations with already low levels of genetic diversity (as in the critically endangered Iberian lynx; Casas-Marce et al. 2017). Such a scenario concurs with the conclusions of Pastor et al. (2007) based on the analysis of microsatellites data, which support (1) recent, strong genetic drift resulting in marked genetic differentiation between the North Atlantic and the eastern Mediterranean populations, and at the same time (2) an imprint of past gene flow across the species' range as suggested by the distribution of allele frequencies.

Insights in the genetic variability of MMS should be used to guide conservation planning for the species, including the discussion on the benefits/risks of translocations and captive breeding programs that could be envisaged to save the species from extinction (Boulva 1979, Johnson et al. 2006, Pastor et al. 2007, Schultz 2011, Karamanlidis et al. 2016b). Our results supporting low genetic variability and past-possibly recentgene flow across the species' range could constitute a new baselinetogether with the conclusions of Pastor et al. (2007)—for the nonexclusive management of the two main extant populations in future conservation strategies. Further studies-notably targeting the nuclear genome-are necessary to give a time estimate to such past events of gene flow and assess the most critical parameters involved in the survival of MMS, notably regarding the issue of inbreeding $v s$. outbreeding depression (see Frankham et al. 2011).

\section{Implications for the Conservation Genetics of the Mediterranean Monk Seal}

The various attempts at assessing patterns of genetic diversity within MMS have highlighted limited genetic variation in the species and the difficulty to find informative, i.e., variable, markers to study/monitor the species (Harwood et al. 1996; Stanley and Harwood 1997; Pastor et al. 2004, 2007; Schultz 2011; Karamanlidis et al. 2016b). Our efforts to expand temporal and geographic coverages to an unprecedented level allowed us to characterize two new haplotypes and three new polymorphic sites on the CR1 fragment of MMS (Fig. 2, Table S3). However, genetic variability within the species remained very low (mean number of nucleotide substitutions $=0.5 \%$; $\min -\max =0.2 \%-1.0 \%$ ), and there was only one mutation $(0.2 \%)$ differentiating the two main CR1 haplotypes mostly characterizing the North Atlantic (MM05) and the eastern Mediterranean (MM01) populations (similar observations apply also to mitogenomes, with only $0.3 \%$ substitutions).

The sequencing of five mitogenomes revealed very low levels of overall mtDNA variation in MMS. No variation was recorded within the four samples sharing the MM01 (CR1) haplotype in the Adriatic and Aegean Sea. Between MM05 and MM01, only seven genes out of 16 showed some level of polymorphism (Table $\mathrm{S} 5$ ), generally ranging between $0.1 \%$ and $0.4 \%$. Genes commonly used in mammalian phylogeography, such as cox 1 and $c y t b$ exhibited very low levels of polymorphism ( 3 and 4 variable sites, respectively). The control region had the highest level of polymorphism (2.4\%; 31 variable sites), although most of the variability 
originated from repeated motifs and indels located in the hypervariable regions, as typically observed in mammals (e.g., Fumagalli et al. 1996).

Given the low levels of polymorphism observed in MMS despite extensive sampling coverage in time and space, our study highlights the limitations of mtDNA in assessing the population dynamics of the species. Moreover, mtDNA constitutes a single locus that may suggest a different scenario than nuclear, multilocus genotyping because of its maternal inheritance, smaller effective population size, and different sensitivity to demographic events such as bottlenecks (e.g., Fay and Wu 1999). However, attempts at generating multilocus nuclear data in MMS-in this case, microsatellites-have so far suffered from very low levels of detected polymorphism (Pastor et al. 2004, 2007, 2011).

Mediterranean monk seals continue to be exposed to a number of substantial threats, including habitat loss and deterioration, and deliberate killing (Karamanlidis and Dendrinos 2015), the latter being the most frequent cause of death in the Aegean Sea and the eastern Mediterranean coast of Turkey (Dede et al. 2015). Because populations are small and fragmented, they are also highly sensitive to diseases and stochastic events such as the mass-mortality event observed at Cabo Blanco in 1997, which killed more than 200 animals (Karamanlidis et al. 2016a). Although the ability of MMS to use marine caves for pupping and shelter may have temporarily saved the species from extinction (Bareham and Furreddu 1975), it will be crucial for its long-term survival to know whether the low genetic diversity observed in the species is associated with inbreeding depression, lower fitness and lower adaptability as predicted in population genetics theory (Lande 1998, Spielman et al. 2004, Frankham 2005).

Following Karamanlidis et al. (2016b), we recommend pursuing the systematic collection of DNA samples throughout the species' range in order to establish a long-term DNA register that will help investigating temporal trends in the genetic diversity of MMS. In this context, additional mtDNA-sequencing from historical samples should allow a more accurate assessment of the species' genetic diversity through time and the refinement of the metapopulation scenario hypothesis posited in this study. In addition, the development of new nuclear markers via highthroughput sequencing technologies, but also investigations on more ancient time frames using archaeozoological samples are promising pathways to unravel the population dynamics of this emblematic species and develop efficient, DNA-assisted conservation strategies.

\section{ACKNOWLEDGMENTS}

We thank all the people who allowed us accessing museum collections, and more particularly Andrea Dall'Asta (Aquario e rettilario del Museo Civico di Storia Naturale di Trieste, Italy), Edoardo Razzetti (Natural History Museum of the University of Pavia, Italy), Massimo Scandura (Università degli Studi di Sassari, Italy), Paolo Agnelli (University of Florence, Natural History Museum, Italy), Maria Rosaria Ghiara (Centro Musei delle Scienze Naturali e Fisiche of the University of Naples "Federico II", Italy), Maria Rosario Sempere Rodriguez (Estacion Biologica de Doñana, Sevilla, Spain), Christine Lefèvre and Anne Previato (Muséum National d'Histoire Naturelle, Paris, France), Marie-Laure Guérin (Musée d'Histoire 
Naturelle de Nantes, France), Daniela Kalthoff (Naturhistoriska riksmuseet, Stockholm, Sweden), Steffen Bock and Christiane Funk (Zoologisches Museum Berlin, Germany), Frank Zachos (Naturhistorisches Museum Wien, Austria), Pepijn Kamminga (Rijksmuseum van Natuurlijke Historie, Leiden, Holland), Melanya Stan ("Grigore Antipa" National Museum of Natural History, Bucarest, Romania), and Petros Lymberakis (Natural History Museum of Crete, Heraklion, Grece). José Antonio Godoy (Estacion Biologica de Doñana) and Spartaco Gippoliti (Giardino Zoologico di Roma, Italy) also helped accessing collections. ED, BO, and AMT thank Ali Cemal Gücü (Middle East Technical University, Institute of Marine Sciences, Mersin Turkey) and Elif Özgür Özbek (Antalya Metropolitan Municipality, Marine Biology Museum, Antalya, Turkey) for their help during field work. At ISEM, historical samples were processed on the ADNdeg platform and capillary electrophoresis was conducted on the GenSeq platform of LabEx CeMEB (Centre Méditerranéen Environnement et Biodiversité). PG received support from the Fondation Prince Albert II de Monaco. We thank Patricia Rosel and three reviewers for their constructive comments on the early draft of the manuscript.

\section{Literature Cited}

Amos, W., and J. Harwood. 1998. Factors affecting levels of genetic diversity in natural populations. Philosophical Transactions of the Royal Society of London, Series B: Biological Sciences 353:177-186.

Bandelt, H., P. Forster and A. Röhl. 1999. Median-joining networks for inferring intraspecific phylogenies. Molecular Biology and Evolution 16:37-48.

Bareham, J. R., and A. Furreddu. 1975. Observations on the use of grottos by Mediterranean Monk seals (Monachus monachus). Journal of Zoology 175: 291-298.

Borrell, A., G. Cantos, A. Aguilar, E. Androukaki and P. Dendrinos. 2007. Concentrations and patterns of organochlorine pesticides and PCBs in Mediterranean monk seals (Monachus monachus) from Western Sahara and Greece. Science of the Total Environment 381:316-325.

Boulva, J. 1979. Mediterranean monk seal. Pages 95-100 in Mammals in the Seas. Pinniped species summaries and report on sirenians. FAO Fisheries Series No. 5, Roma, Italy.

Brito, C. 2012. Portuguese sealing and whaling activities as contributions to understand early northeast Atlantic environmental history of marine mammals. Pages 207-222 in A. Romero and E. O. Keith, eds. New approaches to the study of marine mammals. InTech. Available at https://doi.org/10.5772/54213.

Casas-Marce, M., E. Marmesat, L. Soriano, et al. 2017. Spatiotemporal dynamics of genetic variation in the Iberian lynx along its path to extinction reconstructed with ancient DNA. Molecular Biology and Evolution 34:2893-2907.

Chao, A. 1984. Nonparametric estimation of the number of classes in a population. Scandinavian Journal of Statistics 11:265-270.

Chao, A., C.-H. Chiu, T. C. Hsieh, T. Davis, D. A. Nipperess and D. P. Faith. 2015. Rarefaction and extrapolation of phylogenetic diversity. Methods in Ecology and Evolution 6:380-388.

Colwell, R. K. 2013. EstimateS: Statistical estimation of species richness and shared species from samples. Available at http://viceroy.eeb.uconn.edu /estimates/index.html.

Colwell, R. K., A. Chao, N. J. Gotelli, S.-Y. Lin, C. X. Mao, R. L. Chazdon and J. T. Longino. 2012. Models and estimators linking individual-based and sample-based rarefaction, extrapolation and comparison of assemblages. Journal of Plant Ecology 5:3-21. 
Danyer, E., I. Aytemiz, E. Özgür Özbek and A. M. Tonay. 2013. Preliminary study on a stranding case of Mediterranean monk seal Monachus monachus (Hermann, 1779) on Antalya coast, Turkey, August 2013. Journal of Black Sea/Mediterranean Environment 19:359-364.

Danyer, E., I. Aytemiz, A. Cemal Gücü and A. M. Tonay. 2014. Preliminary study on a stranding case of Mediterranean monk seal Monachus monachus (Hermann, 1779) on the Eastern Mediterranean coast of Turkey. Journal of Black Sea/Mediterranean Environment 20:152-157.

Dede, A., M. A. Tonay and B. Öztürk. 2015. Mediterranean monk seal Monachus monachus (Hermann, 1779) in the Aegean Sea. Pages 612-636 in T. Katağan, A. Tokaç, Ş. Besiktepe and B. Öztürk, eds. The Aegean sea marine biodiversity: Fisheries, conservation and governance. Publication No. 41. Turkish Marine Research Foundation, Istanbul, Turkey.

Dede, A., M. A. Tonay, A. A. Öztürk and B. Öztürk. 2016. Status of the marine mammals population of the Sea of Marmara. Pages 863-879 in E. Özsoy, M. N. Çağatay, N. Balkıs, N. Balkıs and B. Öztürk, eds. The Sea of Marmara: Marine biodiversity, fisheries, conservation and governance. Publication No. 42. Turkish Marine Research Foundation, Istanbul, Turkey.

Edgar, R. 2004. MUSCLE: A multiple sequence alignment method with reduced time and space complexity. BMC Bioinformatics 5:113.

Fay, J. C., and C.-I. Wu. 1999. A human population bottleneck can account for the discordance between patterns of mitochondrial versus nuclear DNA variation. Molecular Biology and Evolution 16:1003-1005.

Foote, A. D., K. Kaschner, S. E. Schultze, et al. 2013. Ancient DNA reveals that bowhead whale lineages survived Late Pleistocene climate change and habitat shifts. Nature Communications 4:1677.

Frankham, R. 2005. Genetics and extinction. Biological Conservation 126:131-140.

Frankham, R., J. D. Ballou, M. D. B. Eldridge, R. C. Lacy, K. Ralls, M. R. Dudash and C. B. Fenster. 2011. Predicting the probability of outbreeding depression. Conservation Biology 25:465-475.

Fumagalli, L., P. Taberlet, L. Favre and J. Hausser. 1996. Origin and evolution of homologous repeated sequences in the mitochondrial DNA control region of shrews. Molecular Biology and Evolution 13:31-46.

Gazo, M., F. Aparicio, M. A. Cedenilla, J. F. Layna and L. M. González. 2000. Pup survival in the Mediterranean Monk Seal (Monachus monachus) colony at Cabo Blanco Peninsula (Western Sahara-Mauritania). Marine Mammal Science 16:158-168.

Gazo, M., J. F. Layna, F. Aparicio, M. A. Cedenilla, L. M. González and A. Aguilar. 2001. Pupping season, perinatal sex ratio and natality rates of the Mediterranean monk seal (Monachus monachus) from the Cabo Blanco colony. Journal of Zoology 249:393-401.

González, L. M. 2015. Prehistoric and historic distributions of the critically endangered Mediterranean monk seal (Monachus monachus) in the eastern Atlantic. Marine Mammal Science 31:1168-1192.

Hall, T. A. 1999. BioEdit: A user-friendly biological sequence alignment and analysis program for Windows 95/98/NT. Nucleic Acids Symposium Series 41:95-98.

Harwood, J., H. Stanley, M.-O. Beudels and C. Vanderlinden. 1996. Metapopulation dynamics of the Mediterranean Monk Seal. Pages 241-257 in D. Mccullough, ed. Metapopulations and wildlife conservation. Island Press, Covelo, CA.

Hernández, M., I. Robinson, A. Aguilar, et al. 1998. Did algal toxins cause monk seal mortality? Nature 393:28.

Inanmaz, Ö. E., Ö. Değirmenci and A. C. Gücü. 2014. A new sighting of the Mediterranean Monk Seal, Monachus monachus (Hermann, 1779), in the Marmara Sea (Turkey). Zoology in the Middle East 60:278-280. 
International Hydrographic Organization. 1953. Limits of oceans and seas. Imprimerie Monégasque, Monte-Carlo, Monaco.

Jakobsson, M., M. D. Edge and N. A. Rosenberg. 2013. The relationship between Fst and the frequency of the most frequent allele. Genetics 193: 515-528.

Johnson, W. M. 2004. Monk seals in post-classical history. The role of the Mediterranean monk seal (Monachus monachus) in European history and culture, from the fall of Rome to the 20th century. Mededelingen 39:1-91.

Johnson, W. M., and D. M. Lavigne. 1999. Monk seals in Antiquity: The Mediterranean monk seal (Monachus monachus) in ancient history and literature. Mededelingen 35:1-101.

Johnson, W. E., J. A. Godoy, F. Palomares, M. Delibes, M. Fernandes, E. Revilla and S. J. O'Brien. 2004. Phylogenetic and phylogeographic analysis of Iberian lynx populations. Journal of Heredity 95:19-28.

Johnson, W. M., A. A. Karamanlidis, P. Dendrinos, et al. 2006. Monk seal fact files. Biology, behaviour, status and conservation of the Mediterranean monk seal, Monachus monachus. The Monachus Guardian. Available at https://www.monachus-guardian.org.

Karamanlidis, A., and P. Dendrinos. 2015. Monachus monachus. The IUCN Red List of Threatened Species 2015:e.T13653A45227543. Available at https:// doi.org/10.2305/IUCN.UK.2015-4.RLTS.T13653A45227543.en.

Karamanlidis, A. A., P. Dendrinos, P. F. De Larrinoa, A. C. Gücü, W. M. Johnson, C. O. Kiraç and R. Pires. 2016a. The Mediterranean monk seal Monachus monachus: Status, biology, threats, and conservation priorities. Mammal Review 46:92-105.

Karamanlidis, A. A., S. Gaughran, A. Aguilar, et al. 2016b. Shaping species conservation strategies using mtDNA analysis: The case of the elusive Mediterranean monk seal (Monachus monachus). Biological Conservation 193:71-79.

Kiraç, C. O. 2011. Conservation of the Mediterranean monk seal Monachus monachus in Turkey and the role of coastal and marine protected areas. Page 41 in E. Hoyt, ed. Proceedings of the Second International Conference on Marine Mammal Protected Areas. Agence des Aires Marines Proteges \& NOAA, Fort-de-France, Martinique, France.

Kovacs, K. M., A. Aguilar, D. Aurioles, et al. 2012. Global threats to pinnipeds. Marine Mammal Science 28:414-436.

Kumar, S., G. Stecher and K. Tamura. 2016. MEGA7: Molecular Evolutionary Genetics Analysis version 7.0 for bigger datasets. Molecular Biology and Evolution 33:1870-1874.

Lande, R. 1998. Anthropogenic, ecological and genetic factors in extinction and conservation. Researches on Population Ecology 40:259-269.

Marchessaux, D. 1989. Distribution et statut des populations du phoque moine Monachus monachus (Hermann, 1779) [Distribution and status of monk seal populations Monachus monachus (Hermann, 1779)]. Mammalia 53:621-642.

Martínez-Jauregui, M., G. Tavecchia, M. A. Cedenilla, T. Coulson, P. Fernández De Larrinoa, M. Muñoz and L. M. González. 2012. Population resilience of the Mediterranean monk seal Monachus monachus at Cabo Blanco peninsula. Marine Ecology Progress Series 461:273-281.

Matocq, M. D., and F. X. Villablanca. 2001. Low genetic diversity in an endangered species: recent or historic pattern? Biological Conservation 98:61-68.

McClenachan, L. and A. B. Cooper. 2008. Extinction rate, historical population structure and ecological role of the Caribbean monk seal. Proceedings of the Royal Society B: Biological Sciences 275:1351-1358.

Meirmans, P. G., and P. W. Hedrick. 2011. Assessing population structure: FST and related measures. Molecular Ecology Resources 11:5-18. 
Milot, E., H. Weimerskirch, P. Duchesne and L. Bernatchez. 2007. Surviving with low genetic diversity: the case of albatrosses. Proceedings of the Royal Society B: Biological Sciences 274:779-787.

Mo, G. 2011. Mediterranean monk seal (Monachus monachus) sightings in Italy (1998-2010) and implications for conservation. Aquatic Mammals 37: 236-240.

Mo, G., H. Bazairi, A. Bayed and S. Agnesi. 2011. Survey on Mediterranean monk seal (Monachus monachus) sightings in Mediterranean Morocco. Aquatic Mammals 37:248-255.

Monod, T. 1932. Phoques sahariens [Saharan seals]. La Terre et la Vie 3: 257-261.

Ok, M., and A. C. Gücü. 2016. Monitoring and conservation of the Mediterranean monk seal in the Turkish part of the Mediterranean Sea. Pages 585-595 in C. Turan, B. Salihoğlu, E. Özbek Özgür and B. Öztürk, eds. The Turkish part of the Mediterranean Sea: Marine biodiversity, fisheries, conservation and governance. Publication No. 43. Turkish Marine Research Foundation, Istanbul, Turkey.

Pastor, T., J. C. Garza, P. Allen, W. Amos and A. Aguilar. 2004. Low genetic variability in the highly endangered Mediterranean monk seal. Journal of Heredity 95:291-300.

Pastor, T., J. C. Garza, A. Aguilar, E. Tounta and E. Androukaki. 2007. Genetic diversity and differentiation between the two remaining populations of the critically endangered Mediterranean monk seal. Animal Conservation 10: 461-469.

Pastor, T., H. L. Cappozzo, E. Grau, W. Amos and A. Aguilar. 2011. The mating system of the Mediterranean monk seal in the Western Sahara. Marine Mammal Science 27:E302-E320.

Polzin, T. and S. V. Daneshmand. 2008. Network 4.5.1.0. User guide. Fluxus Technology, Clare, U.K.

Rodriguez, R., O. Ramirez, C. E. Valdiosera, et al. 2011. 50,000 years of genetic uniformity in the critically endangered Iberian lynx. Molecular Ecology 20: 3785-3795.

Ronald, K., and R. Duguy. 1979. The Mediterranean monk seal. First international conference on the Mediterranean monk seal, Rhodes, Greece, 2-5 May, 1978. United Nations Environment Programme/Pergamon Press, Oxford, U.K.

Rosel, P. E., and L. Rojas-Bracho. 1999. Mitochondrial DNA variation in the critically endangered vaquita Phocoena sinus Norris and MacFarland, 1958. Marine Mammal Science 15:990-1003.

Rosenbaum, H. C., M. G. Egan, P. J. Clapham, et al. 2000. Utility of North Atlantic right whale museum specimens for assessing changes in genetic diversity. Conservation Biology 14:1837-1842.

Rozas, J., A. Ferrer-Mata, J. C. Sánchez-Delbarrio, S. Guirao-Rico, P. Librado, S. E. Ramos-Onsins and A. Sánchez-Gracia. 2017. DnaSP 6: DNA sequence polymorphism analysis of large data sets. Molecular Biology and Evolution 34:3299-3302.

RStudio Team. 2015. RStudio: Integrated Development for R. RStudio, Inc., Boston, MA. Available at http://www.rstudio.com/.

Scheel, D.-M., G. Slater, S.-O. Kolokotronis, et al. 2014. Biogeography and taxonomy of extinct and endangered monk seals illuminated by ancient DNA and skull morphology. ZooKeys 409:1-33.

Schultz, J. K. 2011. Population genetics of the monk seals (genus Monachus): a review. Aquatic Mammals 37:227-235.

Schultz, J. K., J. D. Baker, R. J. Toonen and B. W. Bowen. 2009. Extremely low genetic diversity in the endangered Hawaiian monk seal (Monachus schauinslandi). Journal of Heredity 100:25-33. 
Schultz, J. K., A. J. Marshall and M. Pfunder. 2010. Genome-wide loss of diversity in the critically endangered Hawaiian monk seal. Diversity 2:863-880.

Sergeant, D., K. Ronald, J. Boulva and F. Berkes. 1978. The recent status of Monachus monachus, the Mediterranean monk seal. Biological Conservation 14:259-287.

Spielman, D., B. W. Brook and R. Frankham. 2004. Most species are not driven to extinction before genetic factors impact them. Proceedings of the National Academy of Sciences of the United States of America 101:15261-15264.

Spurgin, L. G., D. J. Wright, M. Van Der Velde, N. J. Collar, J. Komdeur, T. Burke and D. S. Richardson. 2014. Museum DNA reveals the demographic history of the endangered Seychelles warbler. Evolutionary Applications 7: 1134-1143.

Stanley, H. F., and J. Harwood. 1997. Genetic differentiation among subpopulations of the highly endangered Mediterranean monk seal. Pages 97-101 in T. E. Tew, T. J. Crawford, J. W. Spencer, D. P. Stevens, M. B. Usher and $\mathrm{J}$. Warren, eds. The role of genetics in conserving small populations. JNCC (Joint Nature Conservation Committee), Peterborough, U.K.

Steele, T. E., and E. Álvarez-Fernández. 2011. Initial investigations into the exploitation of coastal resources in North Africa during the Late Pleistocene at Grotte des Contrebandiers, Morocco. Pages 383-403 in N. F. Bicho, J. A. Haws and L. G. Davis, eds. Trekking the shore: Changing coastlines and the antiquity of coastal settlement. Springer, New York, NY.

Stringer, C. B., J. C. Finlayson, R. N. E. Barton, et al. 2008. Neanderthal exploitation of marine mammals in Gibraltar. Proceedings of the National Academy of Sciences of the United States of America 105:14319-14324.

Suarez, A. V., and N. D. Tsutsui. 2004. The value of museum collections for research and society. Bioscience 54:66-74.

Tilak, M.-K., F. Justy, M. Debiais-Thibaud, F. Botero-Castro, F. Delsuc and E. P. Douzery. 2015. A cost-effective straightforward protocol for shotgun Illumina libraries designed to assemble complete mitogenomes from nonmodel species. Conservation Genetics Resources 7:37-40.

Trantalidou, K. 2011. From Mesolithic fishermen and bird hunters to neolithic goat herders: The transformation of an island economy in the Aegean. Pages 53-150 in A. Sampson, ed. The cave of the cyclops: Mesolithic and Neolithic networks in the northern Aegean, Greece. Volume I. Intra-site analysis, local industries, and regional site distribution. INSTAP Academic Press, Philadelphia, PA.

Wandeler, P., P. E. A. Hoeck and L. F. Keller. 2007. Back to the future: Museum specimens in population genetics. Trends in Ecology \& Evolution 22:634-642.

Weber, D., B. S. Stewart, J. C. Garza and N. Lehman. 2000. An empirical genetic assessment of the severity of the northern elephant seal population bottleneck. Current Biology 10:1287-1290.

Received: 7 February 2018

Accepted: 26 March 2019

\section{SUPPORTING INFORMATION}

The following supporting information is available for this article online at http://onlinelibrary.wiley.com/doi/10.1111/mms.12604/suppinfo.

Table S1. List of the 40 new Mediterranean monk seals samples used in this study. Haplotype numbering follows Karamanlidis et al. (2016b). 
MM06 and MM07 are new haplotypes. Lines in bold mean that the information relative to the specimens could be double-checked with museum curators/data bank managers. The numbers in green cells refer to samples for which the mitogenomes were sequenced (see Table S2). [Excel file]

Table S2. Details of the mitogenomes of Mediterranean monk seals sequenced in this study. [Excel file]

Table S3. Variable positions in the seven control region haplotypes found in this study. Site positions refer to the mitogenome of Mediterranean monk seal GenBank accession number MG570472. Alignment length was $16,747 \mathrm{bp}$.

Table S4. Mean number of nucleotide differences (below diagonal) and range (above diagonal) in Mediterranean monk seals calculated among and within 12 marine subdivisions of the Mediterranean Sea and the North Atlantic Ocean. The yellow diagonal indicates the mean number of differences within each marine subdivision. MS = Mediterranean Sea $;$ NAO = North Atlantic Ocean.

Table S5. By-gene polymorphism across the mitogenome between the two main breeding populations of Mediterranean monk seals (eastern Mediterranean [ $n=4]$ and Cabo Blanco, North Atlantic Ocean [ $n=1])$.

Figure S1. Individual-based rarefaction curve of the expected number of haplotypes relative to sample size. The gray vertical line marks the sample size of this study $(n=204)$. Extrapolation was made for 408 samples (factor of 2). 